(C) 2017. This manuscript version is made available under the CC-BY-NC-ND 4.0 license http:// creativecommons.org/licenses/by-nc-nd/4.0/

Composites Part B ? (2018) ?-?

Doi: 10.1016/j.compositesb.2017.12.036

\title{
Viscoelastically prestressed polymeric matrix composites - effects of temperature on Charpy impact behaviour
}

\author{
Yang Qin, Kevin S. Fancey* \\ GW Gray Centre for Advanced Materials \\ School of Engineering \& Computer Science \\ University of Hull, Hull HU6 7RX, United Kingdom
}

\begin{abstract}
By applying tensile creep to polymeric fibres, a viscoelastically prestressed polymeric matrix composite (VPPMC) can be produced by removing the creep load before the fibres are moulded into a resin matrix. The viscoelastically strained fibres impart compressive stresses to the surrounding matrix, following curing. Previous work has demonstrated that nylon 6,6 fibre-polyester resin VPPMCs can improve mechanical properties by up to $\sim 50 \%$, compared with control (unstressed) counterparts. This paper focuses on the effect of temperature (from $-25{ }^{\circ} \mathrm{C}$ to $45{ }^{\circ} \mathrm{C}$ ) on these composites, under Charpy impact conditions. It was found that impact energy absorption by the VPPMC samples was greater than their control counterparts over the full temperature range, the increases being $\sim 40 \%$ at $20{ }^{\circ} \mathrm{C}$ and above, reducing to $\sim 20 \%$ at lower temperatures. The principal mechanism for energy absorption from the VPPMC samples was fibrematrix debonding. At lower temperatures however, resin impact toughness decreased, which facilitated energy absorption through matrix cracking. Here, as VPPMC prestress impeded this effect, energy absorption through matrix cracking was more prominent within the control samples and this is believed to be a major contribution to the observed reduction in VPPMC performance relative to control samples at lower temperatures.
\end{abstract}

Keywords: A. Polymer-matrix composites (PMCs); B. Impact behaviour; B. Debonding; Viscoelasticity.

\footnotetext{
* Corresponding author. Tel.: + 441482 465071; fax: +44 1482466664

E-mail address: k.s.fancey@hull.ac.uk (K.S. Fancey).
} 


\section{Introduction}

Previous investigations into viscoelastically prestressed polymeric matrix composites (VPPMCs) have already demonstrated improved mechanical properties relative to control (unstressed) counterparts, without the need to increase section size or weight. In contrast with (more conventional) elastically prestressed polymeric matrix composites (EPPMCs), a key benefit of VPPMC processing is that the fibre stretching and moulding operations are decoupled; i.e. fibres (with appropriate viscoelastic properties) are subjected to tensile creep under a fixed load for a predetermined time and, following load removal, they are moulded into a resin matrix. Following matrix curing, the viscoelastically recovering fibres create compressive prestress in the surrounding matrix, which is counterbalanced by residual tension within the fibres. Therefore, relatively simple equipment is required to apply creep loads to fibre tows. Also, on releasing the load, the unconstrained fibres can be cut to any length, and then positioned in any orientation within any shape of mould that can be filled with a matrix resin [1].

For nylon 6,6 fibre-based VPPMCs, increases of typically 25-50\% have been observed from Charpy impact and flexural stiffness tests [2-6] and $\sim 15 \%$ in tensile strength [7]. Nevertheless, the improved performance provided by VPPMCs must also be considered in terms of product longevity. Localised creep at the fibre-matrix interface regions may be expected to occur as in EPPMCs; for VPPMCs however, this would be offset by active responses from longer term viscoelastic recovery mechanisms within the polymeric fibres [8]. In fact, a recent accelerated ageing study has demonstrated that nylon fibre-based VPPMCs show no deterioration in (room temperature) impact performance for at least 25 years, even after being exposed over that period to a constant ambient temperature of $50{ }^{\circ} \mathrm{C}$ [6].

Although nylon fibre reinforcement has been at the forefront of this research, VPPMCs have also been successfully demonstrated using (mechanically superior) ultra-high molecular weight polyethylene (UHMWPE) fibres, where increases of 20-40\% in flexural modulus and Charpy impact energy absorption have been observed $[9,10]$. Moreover, other researchers have found that the flexural toughness of VPPMCs based on bamboo increased by $28 \%$ [11]. These alternatives do not preclude opportunities for the commercial exploitation of nylon fibre-based VPPMCs however. For example, nylon 6,6 fibres (for generating prestress) could be commingled with more common reinforcing fibres and a study of nylon 6,6-Kevlar fibre hybrid composites has shown that the prestress effect increases impact energy absorption by up to $33 \%$ and flexural modulus by $40 \%$ [12]. Shape-changing (morphing) structures using nylon 6,6 fibre-based VPPMCs have also been recently demonstrated $[13,14]$, which may lead to the design of functional structures, such as morphing aerofoils.

The stage has now been reached where the performance of VPPMCs needs to be considered in terms of ambient temperature, since even the mechanical characteristics of conventional PMCs can be sensitive to thermal effects. Thus in terms of low velocity impact behaviour, Khalid [15] found that Charpy impact energy absorption showed a slight increase with temperature from $-40{ }^{\circ} \mathrm{C}$ to $40{ }^{\circ} \mathrm{C}$ for woven aramid/epoxy and glass/epoxy PMCs. For drop-weight impact, Hirai et al [16] found that energy absorption decreased with increasing temperature $\left(-65^{\circ} \mathrm{C}\right.$ to $\left.100{ }^{\circ} \mathrm{C}\right)$, whilst the damage area increased for glass fabric/vinyl-ester PMCs. Similarly, Amaro et al [17] observed a larger damage area with increasing temperature $\left(\sim 20^{\circ} \mathrm{C}\right.$ to $\left.90^{\circ} \mathrm{C}\right)$ but also found that energy absorption increased for glass fibre reinforced laminates. In contrast, Ibekwe et al [18], showed that both damage area and energy absorption decreased with increasing temperature $\left(-20^{\circ} \mathrm{C}\right.$ to $\left.20{ }^{\circ} \mathrm{C}\right)$ for glass/epoxy PMCs. A study of glass fibre/epoxy composites under cryogenic conditions $\left(-173^{\circ} \mathrm{C}\right.$ to $\left.22^{\circ} \mathrm{C}\right)$ by Ma et al [19] demonstrated smaller damage size and depth together with less energy absorption as the temperature decreased. Most recently, Sorrentino et al [20] found that the type of fibre reinforcement had a significant influence on the effects of temperature on low velocity impact testing. Clearly, these findings suggest that the influence of ambient temperature on PMC mechanical performance could be complex.

To date, all mechanical investigations for VPPMCs have been limited to normal ambient temperature; i.e. $20{ }^{\circ} \mathrm{C}$ [2-10,12-14,21-23]. In real applications however, VPPMCs may be subjected to a wide range of temperatures. Therefore, the purpose of this study was to address this aspect, by investigating the 
mechanical characteristics of nylon 6,6 fibre-based VPPMCs over a range of test temperatures. Charpy impact testing was used since it is a relatively quick and simple procedure.

\section{Experimental procedures}

\subsection{Production of samples}

Batches of composite samples were produced in accordance with previous work [3-6,8,21-23] and procedures are summarised here. Fibre reinforcement was an untwisted continuous nylon 6,6 yarn of 140 filaments with a filament diameter of $27.5 \mu \mathrm{m}$, supplied by Ogden Fibres Ltd, UK. The yarn was annealed in a fan-assisted oven at $150{ }^{\circ} \mathrm{C}$ for $0.5 \mathrm{~h}$ to remove any previous process-related stress history. The yarn was then cut into two identical lengths, one "test", the other "control". A 330 MPa load was applied to the test yarn for $24 \mathrm{~h}$ using a bespoke stretching rig, while the control yarn was placed in close proximity to the stretching rig so that it was exposed to the same ambient conditions $\left(20-21{ }^{\circ} \mathrm{C}, 30-40 \%\right.$ $\mathrm{RH})$. Both yarns were then separately folded, cut into appropriate lengths and brushed into two flat ribbons ready for moulding. Previous studies [5,7,21] have shown no differences in fibre diameter or topography between test and control yarns, resulting from the stretching process.

The matrix material was Reichhold Polylite 32032, a clear (optically transparent) polyester casting resin supplied by MB Fibreglass, UK, mixed with 2\% MEKP catalyst. Unidirectional continuous fibre composite samples were produced by open-casting with two identical aluminium moulds, one for the test samples, the other for the control. Each mould had a polished channel, $10 \mathrm{~mm}$ wide and $3 \mathrm{~mm}$ deep, for moulding a long strip. Test (prestressed) and control (no prestress) strips were moulded simultaneously with the same resin mix. Following demoulding, $\sim 2 \mathrm{~h}$ after casting, both test and control strips were cut into five equal lengths to produce one batch of five test and five control samples, each $80 \times 10 \times 3.2 \mathrm{~mm}$ with a fibre volume fraction of $\sim 2 \%$. All samples were held under weighted steel strips for $24 \mathrm{~h}$ to prevent possible distortion from residual stresses. Finally, samples were stored at room temperature (19$21{ }^{\circ} \mathrm{C}$ ) for $\sim 336 \mathrm{~h}$ (two weeks) prior to impact testing.

\subsection{Cooling and heating calibration curves}

A TAS ECO MT135 environmental chamber $\left(-40^{\circ} \mathrm{C}\right.$ to $100{ }^{\circ} \mathrm{C}$ range) was used for composite sample heating or cooling. The principle here was to pre-heat or cool samples, so that they were at a predesignated temperature at the time of impact testing, the impact test machine being at normal room temperature. To achieve this, cooling and heating curves (temperature against time) of representative samples were measured. Three samples were used (one test, control and matrix-only) and a $5 \mathrm{~mm}$ deep, $1.6 \mathrm{~mm}$ diameter hole was drilled into the edge of each sample to enable insertion of a thermocouple wire; see Fig. 1. Heat sink compound was used to improve thermal conductivity between the wire and sample. The environmental chamber was set to $-35^{\circ} \mathrm{C}$ and $50{ }^{\circ} \mathrm{C}$ for heating and cooling curves respectively, for each of the three samples. After the sample reached the set chamber temperature (within $10 \mathrm{~min}$ ), it was removed from the chamber and the sample temperature was measured at 5 or 10 second intervals for 6 min in an ambient (laboratory) temperature of $20^{\circ} \mathrm{C}$. Cooling and heating curves were measured twice for all three samples to ascertain measurement repeatability. Curve-fits to the data were achieved through CurveExpert 1.4 software.

\subsection{Charpy impact testing and post fracture analysis}

Impact tests were performed with a Ceast Resil 25 Charpy machine using a $7.5 \mathrm{~J}$ hammer at $3.8 \mathrm{~m} / \mathrm{s}$, operating in accordance with BS EN ISO 179 [24]. Five batches of samples were tested under six different test temperatures $\left(-25^{\circ} \mathrm{C},-10{ }^{\circ} \mathrm{C}, 5^{\circ} \mathrm{C}, 20{ }^{\circ} \mathrm{C}, 30{ }^{\circ} \mathrm{C}\right.$ and $\left.45^{\circ} \mathrm{C}\right)$, to ascertain the influence of temperature on composite impact behaviour. Each sample was exposed for $10 \mathrm{~min}$, to $-35^{\circ} \mathrm{C}$ or $50{ }^{\circ} \mathrm{C}$ in the environmental chamber and subsequently impact tested after the designated delay, based on the 
heating or cooling curves. Clearly, samples for testing at $20^{\circ} \mathrm{C}$ did not require heating or cooling. Nevertheless, to determine whether exposure in the environmental chamber had any effect on impact properties at $20{ }^{\circ} \mathrm{C}$, further batches were exposed to $10 \mathrm{~min}$ at either $-35{ }^{\circ} \mathrm{C}$ or $50{ }^{\circ} \mathrm{C}$, then allowed to return to room temperature, for one hour, before impact testing at $20^{\circ} \mathrm{C}$. Subsequently, these results could then be compared with findings from unexposed samples tested at $20^{\circ} \mathrm{C}$.

Previous studies have shown that nylon 6,6 fibres tend to sink to the bottom of a mould before the resin cures. Consequently, all impact tests were performed by positioning samples with the fibre-rich side facing away from the pendulum hammer; a diagram of the configuration has been previously published $[21,22]$. All impact tests were conducted at room temperature $\left(20^{\circ} \mathrm{C}\right)$ and a test span of $24 \mathrm{~mm}$ was used to be consistent with previous work [3-6,8,10,12,21-23]. Hypothesis testing was performed on impact data where necessary, to ascertain if differences in results were statistically significant. All tests were two-tailed and performed at 5\% significance level.

Following Charpy impact testing, samples were analysed in terms of (i) debonded area and (ii) inspection of fractured regions. For (i) photographic images of the debonded regions were enhanced by ImageJ software to facilitate measurement of these areas. For (ii) scanning electron microscopy (SEM) was used to enable investigation of both matrix and fibre damage. Here, fractured samples were made electrically conductive by sputter-coating using a gold target and an S360 SEM (Electron Microscopy Ltd., Cambridge, UK) was employed for subsequent examination.

\section{Results and discussion}

\subsection{Cooling and heating curves}

The cooling and heating curves are shown in Fig. 2. Good repeatability can be seen in both curves with all three sample types and there seems to be little or no difference in temperature-time characteristics. Thus, all specimens could be tested at the same fixed time value to obtain a particular specimen temperature.

Newton's law of cooling [25] was observed to provide a good fit to the cooling curve:

$$
T_{c}(t)=T_{a}+\left(T_{0}-T_{a}\right) e^{-k t}
$$

Here, $T_{\mathrm{c}}(t)$ is the specimen temperature during cooling at time $t$ and $T_{\mathrm{a}}$ is the ambient temperature (an average value during measurement of $20.4^{\circ} \mathrm{C}$ was used). $T_{0}$ represents the initial specimen temperature (i.e. $50^{\circ} \mathrm{C}$ ) and $k$ is a constant related to the specimen heat capacity and its exposed area.

It was found that the heating curve could not be described by Eq. (1) or any other simple relationship. Instead, the best-fit curve was obtained from the following function:

$$
T_{h}(t)=\frac{a+b t}{1+c t+d t^{2}}
$$

Where $T_{\mathrm{h}}(t)$ is the specimen temperature during heating at time $t ; a, b, c$ and $d$ are constants. 


\section{Table 1}

Time delay values (from Fig. 2) required for pre-determined impact test temperatures.

\begin{tabular}{cccccc}
\hline & \multicolumn{3}{c}{ From heating curve } & \multicolumn{2}{c}{ From cooling curve } \\
\hline Test temperature $\left({ }^{\circ} \mathrm{C}\right)$ & -25 & -10 & 5 & 30 & 45 \\
\hline Time $(\mathrm{s})$ & 10.5 & 30.5 & 79.6 & 107.5 & 17.6 \\
\hline
\end{tabular}

From the fitted curves, the time delay between removing samples from the environmental chamber and conducting Charpy impact testing could be determined, and the results are shown in Table 1.

\subsection{Charpy impact tests}

It is well known that the mechanical properties of polymers are highly sensitive to temperature, especially when close to the glass transition temperature $\left(T_{\mathrm{g}}\right)$, which is typically $\sim 70{ }^{\circ} \mathrm{C}$ for polyester [26]. Impact test data from three batches ( 5 samples per batch) of matrix-only samples at each temperature are shown in Fig. 3. It is clear that compared to the results at room temperature $\left(20^{\circ} \mathrm{C}\right)$, the energy absorbed at lower temperatures $\left(-25{ }^{\circ} \mathrm{C}\right.$ to $\left.5^{\circ} \mathrm{C}\right)$ is reduced by $30 \%$, this being constant at $\sim 1.3 \mathrm{~kJ} / \mathrm{m}^{2}$. This consistency in energy absorption at lower temperatures is verified by hypothesis testing. Above $20{ }^{\circ} \mathrm{C}$, impact energy increases with temperature, the energy absorption at $45^{\circ} \mathrm{C}$ being $\sim 30 \%$ higher than at $20{ }^{\circ} \mathrm{C}$. Although impact toughness increases above $20^{\circ} \mathrm{C}$, all matrix-only samples failed by brittle fracture, as would be expected, since test temperatures were below $T_{\mathrm{g}}$.

Fig. 3 also shows larger error bars at the two highest temperatures $\left(30^{\circ} \mathrm{C}\right.$ and $\left.45^{\circ} \mathrm{C}\right)$. Random variations in impact data (within each batch and between batches) were observed to be greater than those at the lower temperatures. Although there was little evidence of change in the brittle fracture characteristics, we suggest there was a greater contribution to impact energy absorption from elastic deflection (prior to brittle fracture) during the impact test at the higher temperatures. Thus minor differences in sample deflection during the impact event may have exacerbated frictional (energy absorbing) variations occurring between sample surfaces and anvil supports.

Composite sample impact test data are shown in Fig. 4. Of major importance here is that the impact energy absorbed by all test samples is higher than their control counterparts, thus demonstrating that viscoelastically generated prestress can function over a practical range of temperatures. The impact energy from control samples decreases with increasing temperature above $-10{ }^{\circ} \mathrm{C}$. Similarly, the test samples show a decrease with rising temperature, though this only becomes apparent above $20^{\circ} \mathrm{C}$. Hypothesis testing reveals no significant difference in energy absorption values for test samples, between $-25^{\circ} \mathrm{C}$ to $20{ }^{\circ} \mathrm{C}$. The relative insensitivity to temperature of both control and (in particular) test samples at low temperatures may, to some extent, be attributed to the unvarying impact energy absorption values of the matrix-only samples from $-25^{\circ} \mathrm{C}$ to $5{ }^{\circ} \mathrm{C}$ in Fig. 3 .

In terms of the energy absorption increase between test and control samples, Fig. 4 clearly shows a difference between lower and higher temperatures, i.e. $\sim 40 \%$ improvement from $20{ }^{\circ} \mathrm{C}$ to $45{ }^{\circ} \mathrm{C}$ but this is reduced to $\sim 20 \%$ between $-25^{\circ} \mathrm{C}$ and $5{ }^{\circ} \mathrm{C}$. Hypothesis testing shows no significant change between the percentage increases from $20^{\circ} \mathrm{C}$ to $45^{\circ} \mathrm{C}$, or for those below $20^{\circ} \mathrm{C}$. 


\section{Table 2}

Impact test results for composite sample batches at room temperature $\left(20^{\circ} \mathrm{C}\right)$ after being exposed to $50{ }^{\circ} \mathrm{C}$ or $-35^{\circ} \mathrm{C}$ for 10 min compared with conventional $20^{\circ} \mathrm{C}$ data used in Fig. 4; SE represents the standard error of the mean.

\begin{tabular}{ccccc}
\hline \multirow{2}{*}{$\begin{array}{c}\text { Testing } \\
\text { conditions }\end{array}$} & \multicolumn{2}{c}{ Mean impact energy $\left(\mathrm{kJ} / \mathrm{m}^{2}\right)$} & $\begin{array}{c}\text { Increase in } \\
\text { energy }(\%)\end{array}$ & $\begin{array}{c}\text { Mean increase in } \\
\text { energy }(\% \pm \mathrm{SE})\end{array}$ \\
\cline { 2 - 4 } $50{ }^{\circ} \mathrm{C}$ to $20{ }^{\circ} \mathrm{C}$ & $31.9 \pm 1.0$ & $20.9 \pm 0.6$ & 52.7 & $44.3 \pm 4.7$ \\
& $33.4 \pm 1.3$ & $24.5 \pm 1.2$ & 36.3 & $43.9 \pm 1.1$ \\
$-35{ }^{\circ} \mathrm{C}$ to $20{ }^{\circ} \mathrm{C}$ & $34.3 \pm 2.7$ & $23.8 \pm 0.7$ & 42.6 & $43.4 \pm 4.9$ \\
& $32.0 \pm 0.9$ & $21.9 \pm 0.7$ & 46.0 & \\
& $30.4 \pm 1.8$ & $21.3 \pm 0.8$ & 43.1 & \\
& $34.2 \pm 3.1$ & $26.1 \pm 0.8$ & 31.3 & \\
& $35.4 \pm 3.2$ & $26.0 \pm 0.8$ & 36.5 & \\
& $32.7 \pm 1.1$ & $23.5 \pm 1.4$ & 39.2 & \\
& $37.3 \pm 4.0$ & $24.1 \pm 1.0$ & 55.1 & \\
& $32.6 \pm 2.4$ & $21.0 \pm 0.7$ & 55.2 & \\
\hline
\end{tabular}

To determine whether environmental chamber exposure had any effect on the mechanical properties of composite samples, additional impact test data at $20^{\circ} \mathrm{C}$ are shown in Table 2. Referring to Section 2.3, each batch ( 3 batches for each condition) of composite samples was subjected to $-35{ }^{\circ} \mathrm{C}$ or $50{ }^{\circ} \mathrm{C}$ for 10 min (as for the tests in Fig. 4) but were then left for one hour to reach room temperature before impact testing. Comparing the results from these two conditions with the conventional data from $20{ }^{\circ} \mathrm{C}$ (i.e. no heating or cooling) in Table 2, there are no significant differences in energy absorption, as confirmed by hypothesis testing. Thus it may be concluded that exposure in the environmental chamber had no influence on composite impact properties and results in Fig. 4 can be attributed only to the effects of sample temperature at the time of impact.

\subsection{Fracture mechanism studies}

Fracture characteristics from typical samples impact tested at $-25^{\circ} \mathrm{C}, 20^{\circ} \mathrm{C}$ and $45^{\circ} \mathrm{C}$ are shown in Fig. 5. All samples show a centre fracture caused by the pendulum hammer impact. There are also two vertical cracks either side of the major fracture site for samples tested at $-25^{\circ} \mathrm{C}$ and $20{ }^{\circ} \mathrm{C}$; these vertical cracks are associated with samples being forced through the anvil shoulders of the Charpy machine during the impact process. There is no evidence of these vertical cracks at $45^{\circ} \mathrm{C}$, however. This may be attributed to the tougher matrix (as indicated in Fig. 3) impeding this type of crack formation at the higher temperature. The lighter regions that can be observed in the samples are areas of fibre-matrix debonding. All test samples show an increased area of debonding compared with control counterparts, and for both test and control samples, larger debonded areas are observed at the lower temperature.

As discussed in previous papers [3,22], debonding is one of the most significant energy absorption mechanisms in the test and control samples. This characteristic therefore requires further consideration. In accordance with Ref. [3], debonded areas are plotted in Fig. 6 over the full temperature range, by assuming the degree of debonding was consistent through the sample thickness. As temperature is increased, two observations can be made: (i) debonded areas for both test and control samples 
progressively decrease and (ii) although there is some fluctuation, the increased area of debonding from the test samples (relative to control) remains approximately constant at $\sim 110 \%$. This is verified by hypothesis testing which shows no significant difference between any two values.

A number of researchers [27-31], have demonstrated that the bonding or interfacial shear strength can deteriorate significantly with increasing temperature for fibre reinforced composites, due to the different coefficients of thermal expansion (CTE) between matrix and fibres. Consequently, when a growing crack in the matrix approaches the fibre-matrix interface, thermally induced stresses may enable the crack to propagate along the interface more readily than to shear through the fibres during the impact process, since less energy would be required. This implies larger debonded areas at higher temperatures, which is in contrast with observations from Fig. 5 and the results in Fig. 6. For conventional PMCs with glass or carbon fibre reinforcement, the CTE values for these fibres can be a factor of 10 lower than the polymer matrix materials. For our composite samples however, the CTE values for nylons $\left(80-95 \times 10^{-6}\right.$ $\left.\mathrm{K}^{-1}\right)$ and polyester resins $\left(50-100 \times 10^{-6} \mathrm{~K}^{-1}\right)$ are comparable [26]. Thus thermal mismatch effects may have a relatively insignificant effect on debonding in our study. Moreover, in contrast with thermoplastic resins, the fibre-matrix interfaces in our thermoset polyester resin composites are said to be formed through chemical bonds, which could further reduce the influence of temperature on interfacial bonding or shear strength [31-33].

As discussed earlier, in relation to Figs. 3 and 5, the matrix material becomes less brittle at higher temperatures. Moreover, since the fibre material is also a polymer, this can be expected to follow a similar trend. Thus a possible explanation for the reduction in debonded areas with increasing temperature in Fig. 6 is that both fibre and matrix materials become less brittle, which could impede interfacial debonding behaviour. This would lead to the observed reduction in impact energy absorption (for both test and control samples) with increasing temperature, as shown in Fig. 4. In addition, the relatively consistent increase $(\sim 110 \%)$ in Fig. 6 could suggest that temperature has a similar influence on the debonded area for both test and control samples from $-25{ }^{\circ} \mathrm{C}$ to $45^{\circ} \mathrm{C}$.

To provide a further understanding of the energy absorption mechanisms, Fig. 7 shows SEM micrographs representing typical fracture behaviour for both test and control samples at $-25{ }^{\circ} \mathrm{C}, 20^{\circ} \mathrm{C}$ and $45^{\circ} \mathrm{C}$. These images clearly show evidence of energy absorption through matrix cracking, fibre fracture and fibre pull-out with bridging by fibres between crack faces. For both test and control samples tested at $45^{\circ} \mathrm{C}$, almost all fibres fracture with just one single central crack in the matrix. In contrast, at $-25{ }^{\circ} \mathrm{C}$, the images show multiple cracks at the fracture zone and fewer fibre fractures in both samples. Therefore, there is clear evidence that the fracture characteristics are strongly associated with temperature. Thus, as the temperature is decreased, the fracture regions show (i) more matrix cracks, and (ii) fewer fibre fractures.

As demonstrated by Fig. 3, the matrix impact toughness decreases at lower temperatures. It is also suggested that the matrix, being more brittle at lower temperatures, may facilitate crack propagation [18] and this concurs with more matrix cracks observed in Fig. 7 as the temperature decreases. In terms of fibre reinforcement, the tensile strength of most polymer fibres (including nylon) increases with decreasing temperature [34,35], which supports the observed reduction in fibre fractures as temperature decreases in Fig. 7. Fewer fibre fractures would enable greater impact load support from the fibres as temperature is reduced, through fibre pull-out (bridging). This in turn could be expected to encourage multiple cracking (in addition to matrix brittleness) instead of the single major crack as observed at $45^{\circ} \mathrm{C}$ in Fig. 7(c).

For samples at $-25^{\circ} \mathrm{C}$ and to a lesser extent at $20{ }^{\circ} \mathrm{C}$ (Figs. 7(a) and 7(b)), the test samples show fewer matrix cracks than their control counterparts. This may be attributed to compressive stresses within the matrix, as these are expected to impede crack formation and propagation $[4,36]$. At $45^{\circ} \mathrm{C}$ however, the greater matrix impact toughness and lower fibre strength may be more prominent than the influence of prestress, thereby leading to a similar fracture characteristic (single matrix crack) for both test and control samples. 
At lower temperatures, larger debonded areas, more matrix cracks and fibre pull-out (bridging) for both test and control samples are observed from Figs. 5 and 7. Clearly, these are mechanisms which concur with the inverse relationship between composite impact energy absorption and temperature in Fig. 4. As previously noted, the increase in energy absorption between test and control samples at lower temperatures in Fig. 4 is relatively small, at $\sim 20 \%$. There is a clear indication here, that energy absorption from the control samples is high and, as demonstrated (in particular) by Fig. 7(a), a contributing factor may be the increased level of matrix cracking in these samples at the lower temperatures.

Fig. 8 shows approximately linear relationships between composite impact energy absorption and debonded area over the range of temperatures studied. The test sample gradient is $\sim 50 \%$ of the control value, indicating that energy absorption in the test samples requires larger areas of debonding than the control samples. It is known that energy absorption from viscoelastically generated prestress depends principally on shear stresses actuating prestress-enhanced fibre-matrix debonding during the impact process [3,37]. Thus it can be inferred that the debonding mechanism contributes to a greater proportion of energy absorbed by the test samples; i.e. the control samples may absorb less energy through debonding and more through other mechanisms. This is exemplified by the increased matrix cracking within the control samples at lower temperatures, as discussed above. The control samples will tend to absorb more energy through matrix cracking at lower temperatures, so that the debonding effect becomes less significant; this in turn can be expected to contribute to the steeper gradient in Fig. 8 .

\section{Conclusion}

Charpy impact tests on nylon 6,6 fibre/polyester resin VPPMC samples have been performed over a range of temperatures, from $-25^{\circ} \mathrm{C}$ to $45^{\circ} \mathrm{C}$. The main findings are:

(i) The impact energy absorbed by VPPMC (test) samples was higher than corresponding unstressed (control) samples over the full range of temperatures studied. In addition, the energy absorbed by both test and control samples decreased with increasing temperature. The increase in energy absorption from test samples was $\sim 40 \%$ at higher temperatures $\left(\geq 20{ }^{\circ} \mathrm{C}\right)$, reducing to $\sim 20 \%$ at lower temperatures. The principal mechanism for energy absorption from the test samples was fibre-matrix debonding.

(ii) At lower temperatures $\left(<20^{\circ} \mathrm{C}\right)$ the polymer resin impact toughness was reduced, which facilitated matrix cracking within the composite samples. This was more prominent within the control samples, as prestress within the test samples impeded matrix cracking. Therefore matrix cracking contributed towards an increase in energy absorption by the control samples, so that the energy absorbed by debonding within the test samples would become less significant. This is believed to be a major contribution to the observed reduction in increased energy absorption between test and control samples at lower temperatures.

Our work has demonstrated that VPPMCs possess a higher impact toughness, compared with unstressed counterparts over a wide range of operating temperatures. Clearly, this is an important aspect for practical engineering applications.

\section{Acknowledgements}

Support from the Hull-China Scholarship Council scheme, for one of the authors (YQ), is gratefully acknowledged. The authors also wish to thank Garry Robinson from the School of Engineering \& Computer Science for SEM technical support. 


\section{References}

[1] Fancey KS. Viscoelastically prestressed polymeric matrix composites: An overview. J Reinf Plast Compos 2016;35(17):1290-301.

[2] Pang JWC, Fancey KS. The flexural stiffness characteristics of viscoelastically prestressed polymeric matrix composites. Compos Part A 2009;40(6):784-90.

[3] Fazal A, Fancey KS. Viscoelastically prestressed polymeric matrix composites - Effects of test span and fibre volume fraction on Charpy impact characteristics. Compos Part B 2013;44(1):472-9.

[4] Fancey KS. Viscoelastically prestressed polymeric matrix composites - Potential for useful life and impact protection. Compos Part B 2010;41(6):454-61.

[5] Wang B, Fancey KS. Towards optimisation of load-time conditions for producing viscoelastically prestressed polymeric matrix composites. Compos Part B 2016;87:336-42.

[6] Fancey KS, Fazal A. Prestressed polymeric matrix composites: Longevity aspects. Polym Compos 2015;37(3):2092-7.

[7] Pang JW, Fancey KS. Analysis of the tensile behaviour of viscoelastically prestressed polymeric matrix composites. Compos Sci Technol 2008;68(7):1903-10.

[8] Fancey KS. Fiber-reinforced polymeric composites with viscoelastically induced prestress. J Adv Mater 2005;37(2):21-9.

[9] Fazal A, Fancey KS. Viscoelastically generated prestress from ultra-high molecular weight polyethylene fibres. J Mater Sci 2013;48(16):5559-70.

[10] Fazal A, Fancey KS. UHMWPE fibre-based composites: Prestress-induced enhancement of impact properties. Compos Part B 2014;66:1-6.

[11] Cui HX, Guan MJ, Zhu YX, Zhang ZZ. The flexural characteristics of prestressed bamboo slivers reinforced parallel strand lumber (PSL). Key Eng Mater 2012;517:96-100.

[12] Fazal A, Fancey KS. Performance enhancement of nylon/kevlar fiber composites through viscoelastically generated pre-stress. Polym Compos 2014;35(5):931-8.

[13] Wang B, Fancey KS. A bistable morphing composite using viscoelastically generated prestress. Mater Lett 2015;158:108-10.

[14] Wang B, Ge C, Fancey KS. Snap-through behaviour of a bistable structure based on viscoelastically generated prestress. Compos Part B 2017;114:23-33.

[15] Khalid AA. The effect of testing temperature and volume fraction on impact energy of composites. Mater Des 2006;27(6):499-506.

[16] Hirai Y, Hamada H, Kim J-K. Impact response of woven glass-fabric composites - II. Effect of temperature. Compos Sci Technol 1998;58(1):119-28.

[17] Amaro AM, Reis PNB, Neto MA. Experimental study of temperature effects on composite laminates subjected to multi-impacts. Compos Part B 2016;98:23-9.

[18] Ibekwe SI, Mensah PF, Li G, Pang S-S, Stubblefield MA. Impact and post impact response of laminated beams at low temperatures. Compos Struct 2007;79(1):12-7.

[19] Ma H-1, Jia Z, Lau K-t, Leng J, Hui D. Impact properties of glass fiber/epoxy composites at cryogenic environment. Compos Part B 2016;92:210-7.

[20] Sorrentino L, Vasconcellos DS, D'Auria M, Sarasini F, Tirillò J. Effect of temperature on static and low velocity impact properties of thermoplastic composites. Compos Part B 2017;113:10010 .

[21] Fancey KS. Investigation into the feasibility of viscoelastically generated pre-stress in polymeric matrix composites. Mater Sci Eng A 2000;279(1):36-41. 
[22] Fancey KS. Prestressed polymeric composites produced by viscoelastically strained nylon 6,6 fibre reinforcement. J Reinf Plast Compos 2000;19(15):1251-66.

[23] Pang JW, Fancey KS. An investigation into the long-term viscoelastic recovery of Nylon 6,6 fibres through accelerated ageing. Mater Sci Eng A 2006;431(1):100-5.

[24] BS EN ISO 179-1:2010. Plastics - Determination of Charpy impact properties.

[25] Winterton R. Newton's law of cooling. Contemp Phys 1999;40(3):205-12.

[26] Ashby MF, Jones DRH. Engineering materials 2: An introduction to microstructures, processing and design: Butterworth-Heinemann; 2013.

[27] Thomason J, Yang L. Temperature dependence of the interfacial shear strength in glass-fibre polypropylene composites. Compos Sci Technol 2011;71(13):1600-5.

[28] Thomason J, Yang L. Temperature dependence of the interfacial shear strength in glass-fibre epoxy composites. Compos Sci Technol 2014;96:7-12.

[29] Miwa M, Liu Y, Tsuzuki H, Takeno A, Watanabe A. Relation between axial compressive strength of reinforcing fibres and fibre diameter. J Mater Sci 1996;31(2):499-506.

[30] Harris B. Shrinkage stresses in glass/resin composites. J Mater Sci 1978;13(1):173-7.

[31] Di Landro L, Pegoraro M. Evaluation of residual stresses and adhesion in polymer composites. Compos Part A 1996;27(9):847-53.

[32] Parlevliet PP, Bersee HE, Beukers A. Residual stresses in thermoplastic composites-a study of the literature. Part III: Effects of thermal residual stresses. Compos Part A 2007;38(6):1581-96.

[33] Chawla KK. Composite materials: science and engineering: Springer Science \& Business Media; 2012.

[34] Crawford RJ. Plastics Engineering: Butterworth-Heinemann; 1998.

[35] Intech Corporation, US. Effects of Temperature and Moisture. [accessed May 2017]; http://www.intechpower.com/material-information/effects-of-temperature-and-moisture.

[36] Motahhari S, Cameron J. Fibre prestressed composites: improvement of flexural properties through fibre prestressing. J Reinf Plast Compos 1999;18(3):279-88.

[37] Motahhari S, Cameron J. Impact strength of fiber pre-stressed composites. J Reinf Plast Compos 1998;17(2):123-30. 


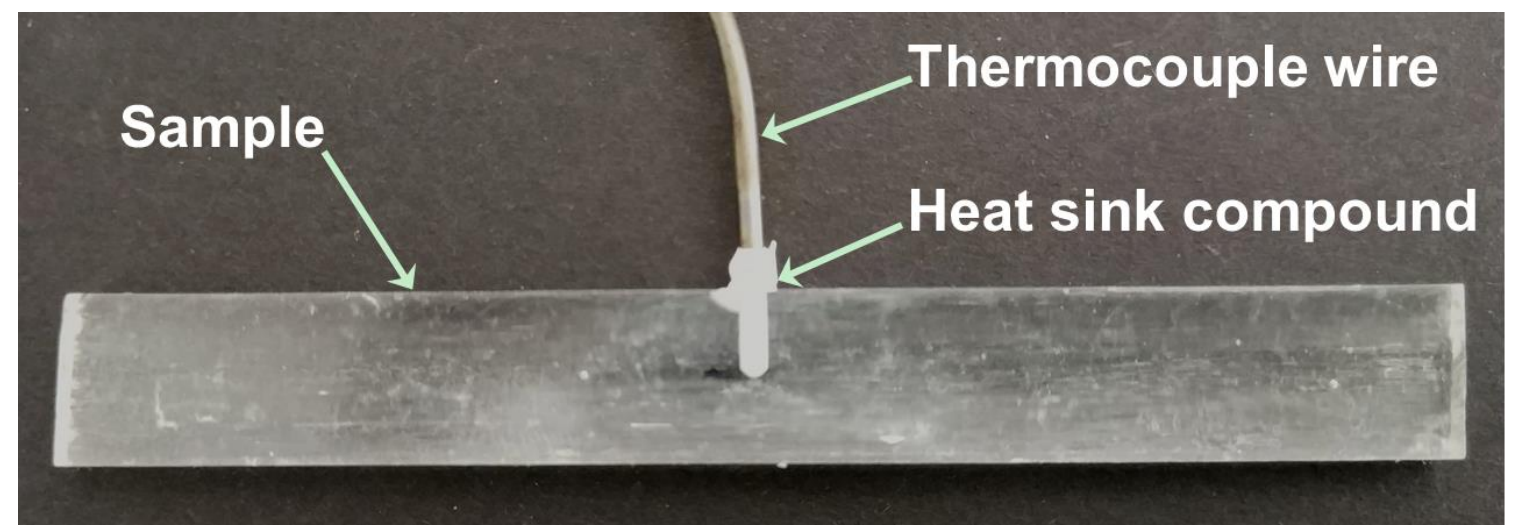

Fig. 1. A representative sample with thermocouple wire (inserted into hole drilled from upper edge) and heat sink compound for determination of the cooling and heating curves.

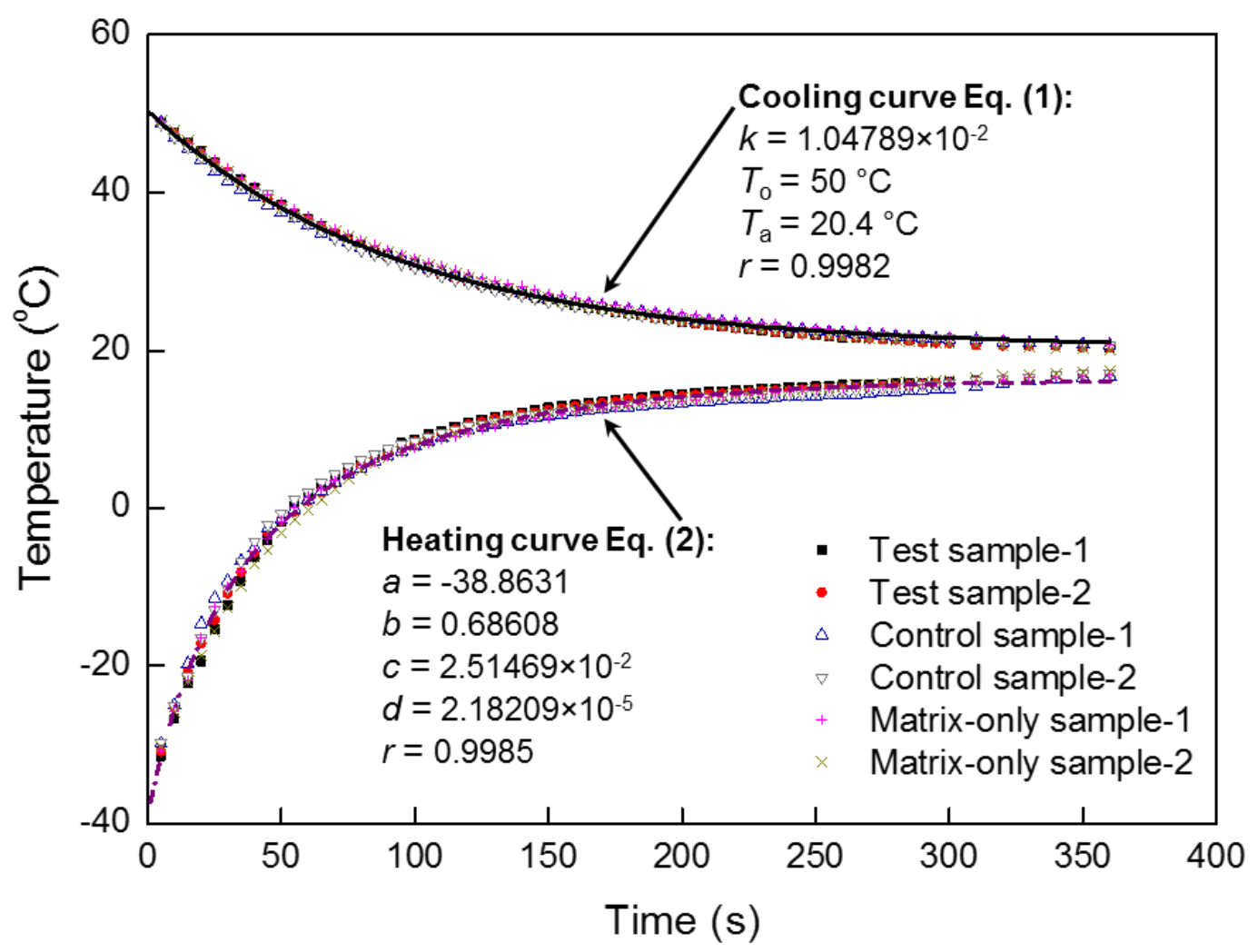

Fig. 2. Cooling and heating curves for test, control and matrix-only samples with curve-fit parameters; $r$ is the correlation coefficient. 


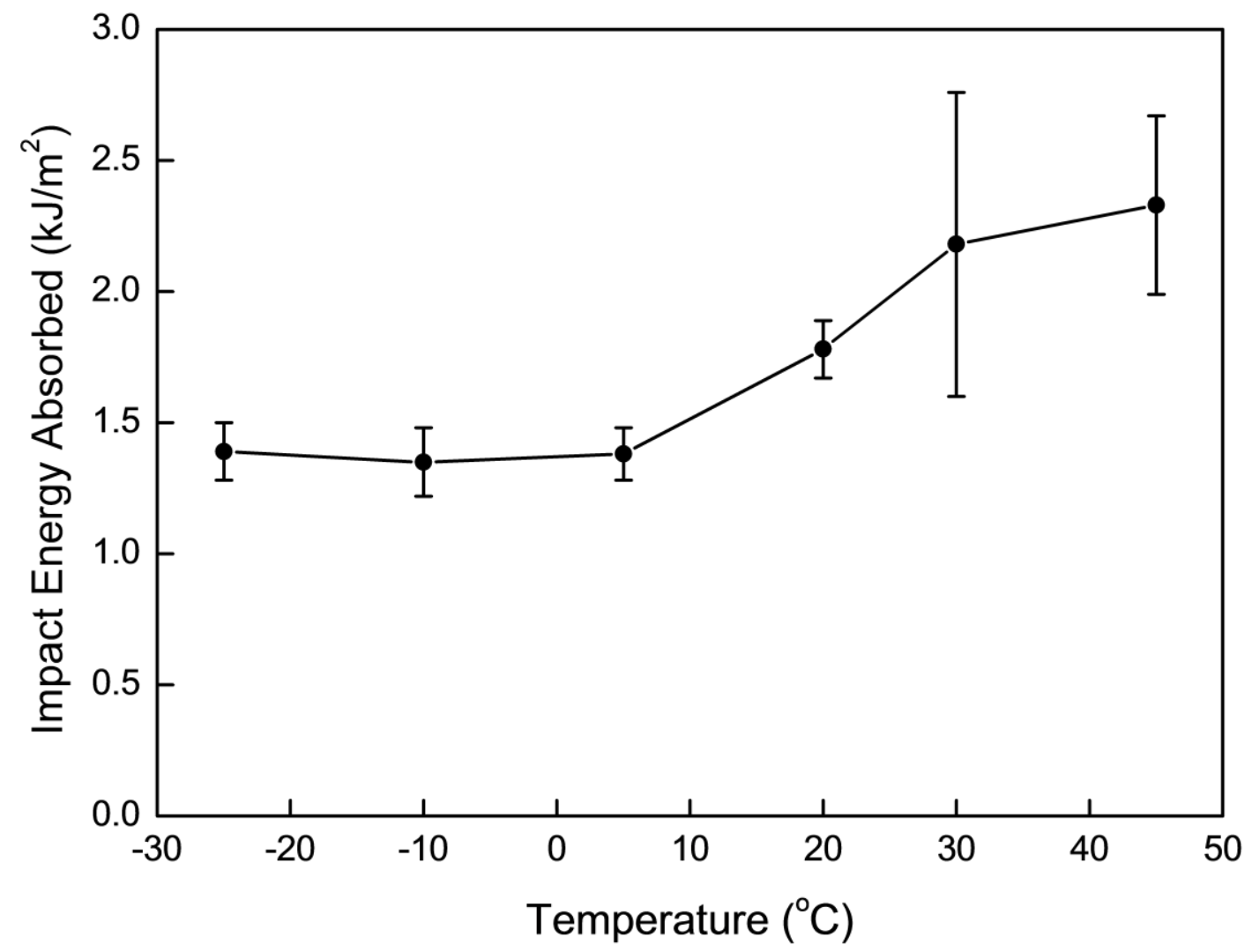

Fig. 3. Impact test results for polyester matrix-only samples; three batches (i.e. 15 samples) at each temperature. Error bars indicate the standard error.

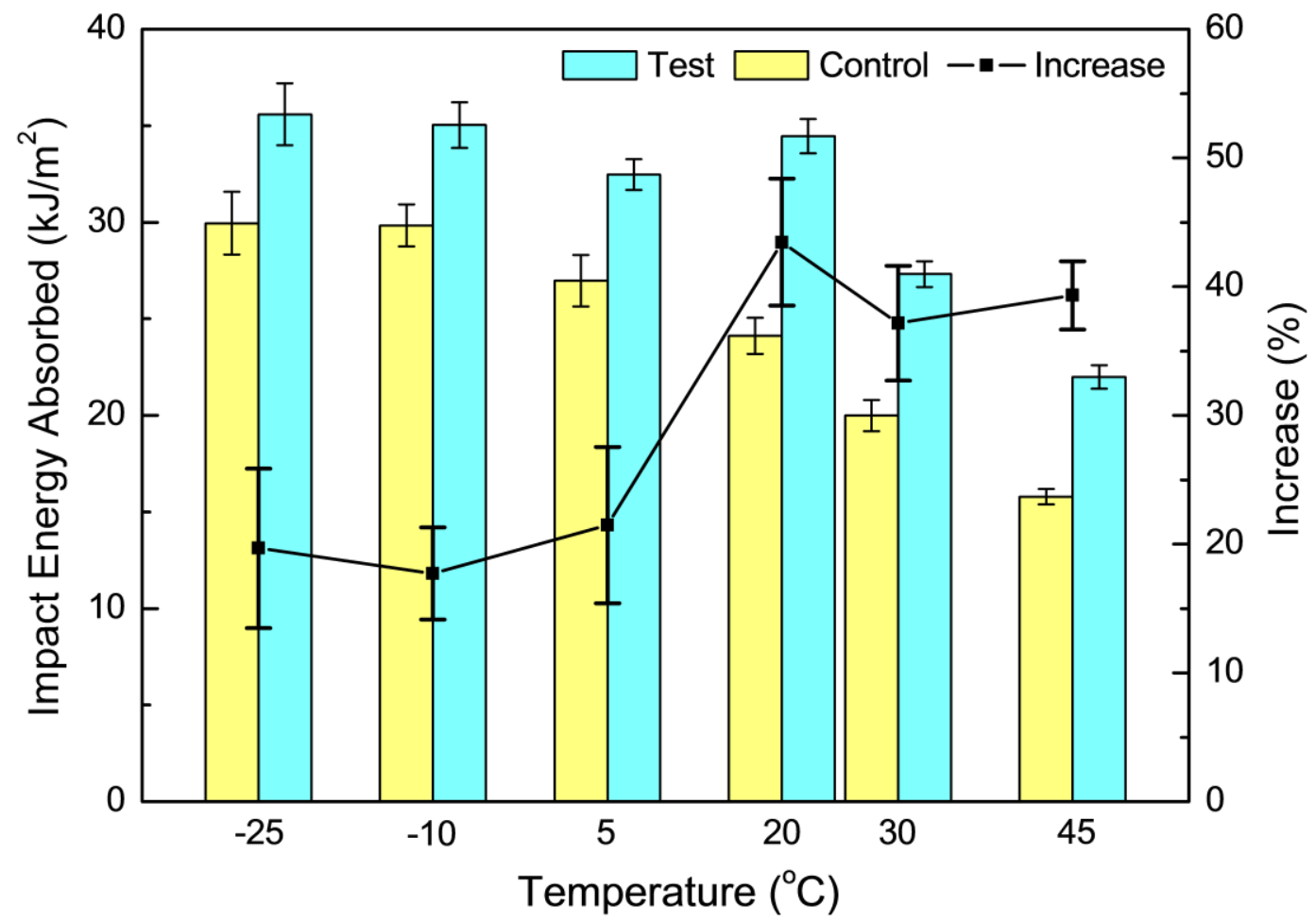

Fig. 4. Impact test results for both test and control samples; five batches (i.e. 25 test, 25 control) at each temperature. Error bars indicate the standard error. 


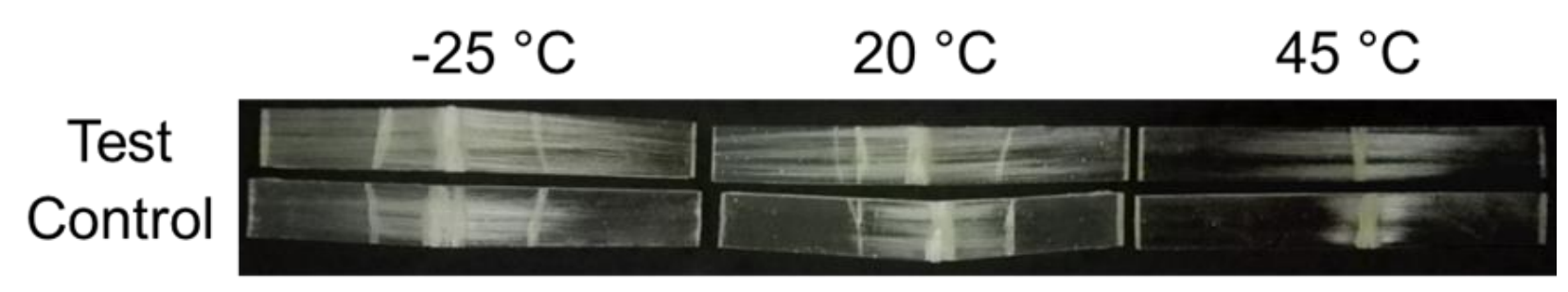

Fig. 5. Typical fracture and debonding characteristics of test and control samples at $-25^{\circ} \mathrm{C}, 20^{\circ} \mathrm{C}$ and $45^{\circ} \mathrm{C}$.

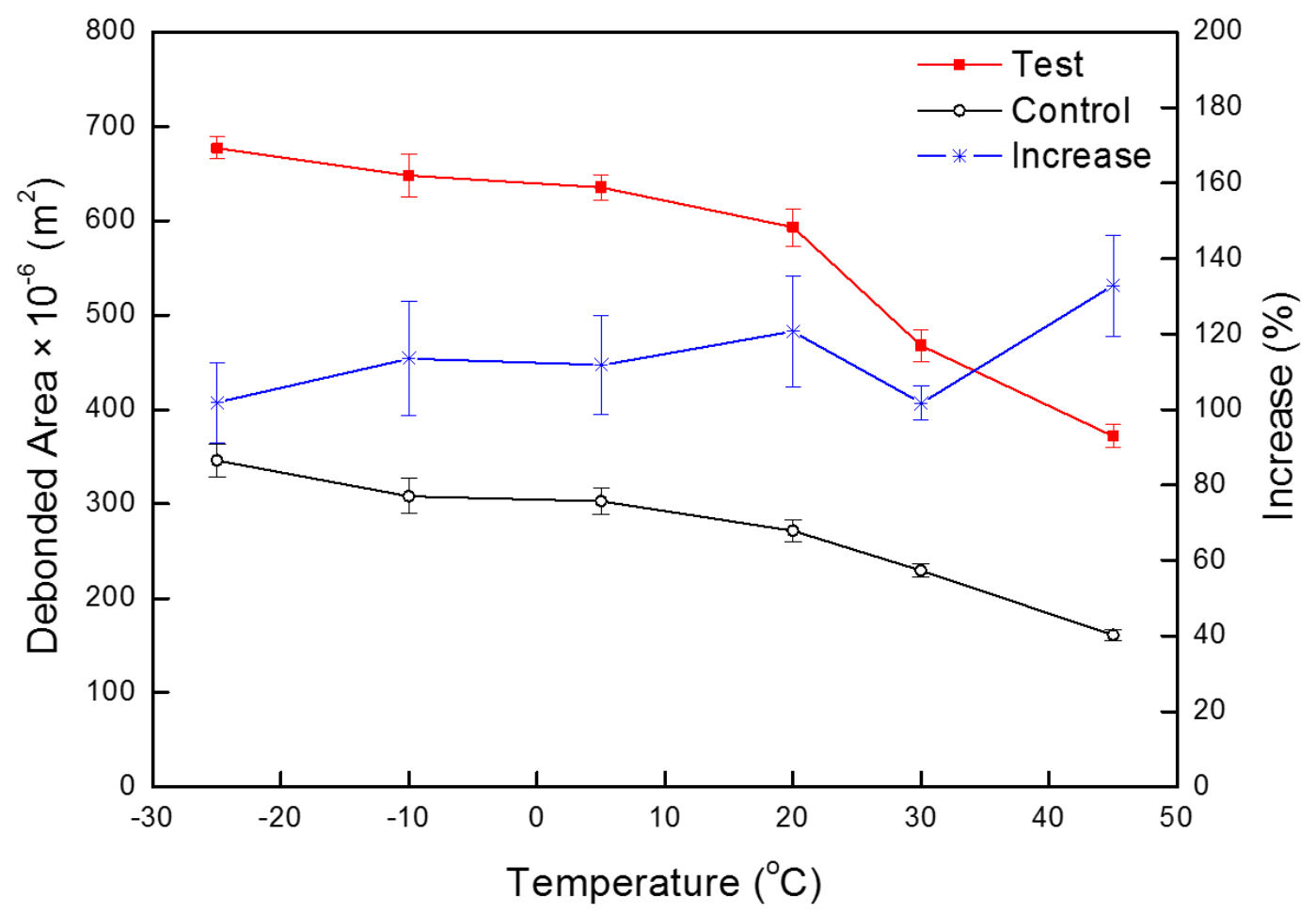

Fig. 6. Debonded area values for both test and control samples and the increase between them from $25^{\circ} \mathrm{C}$ to $45^{\circ} \mathrm{C}$; error bars indicate the standard error. 

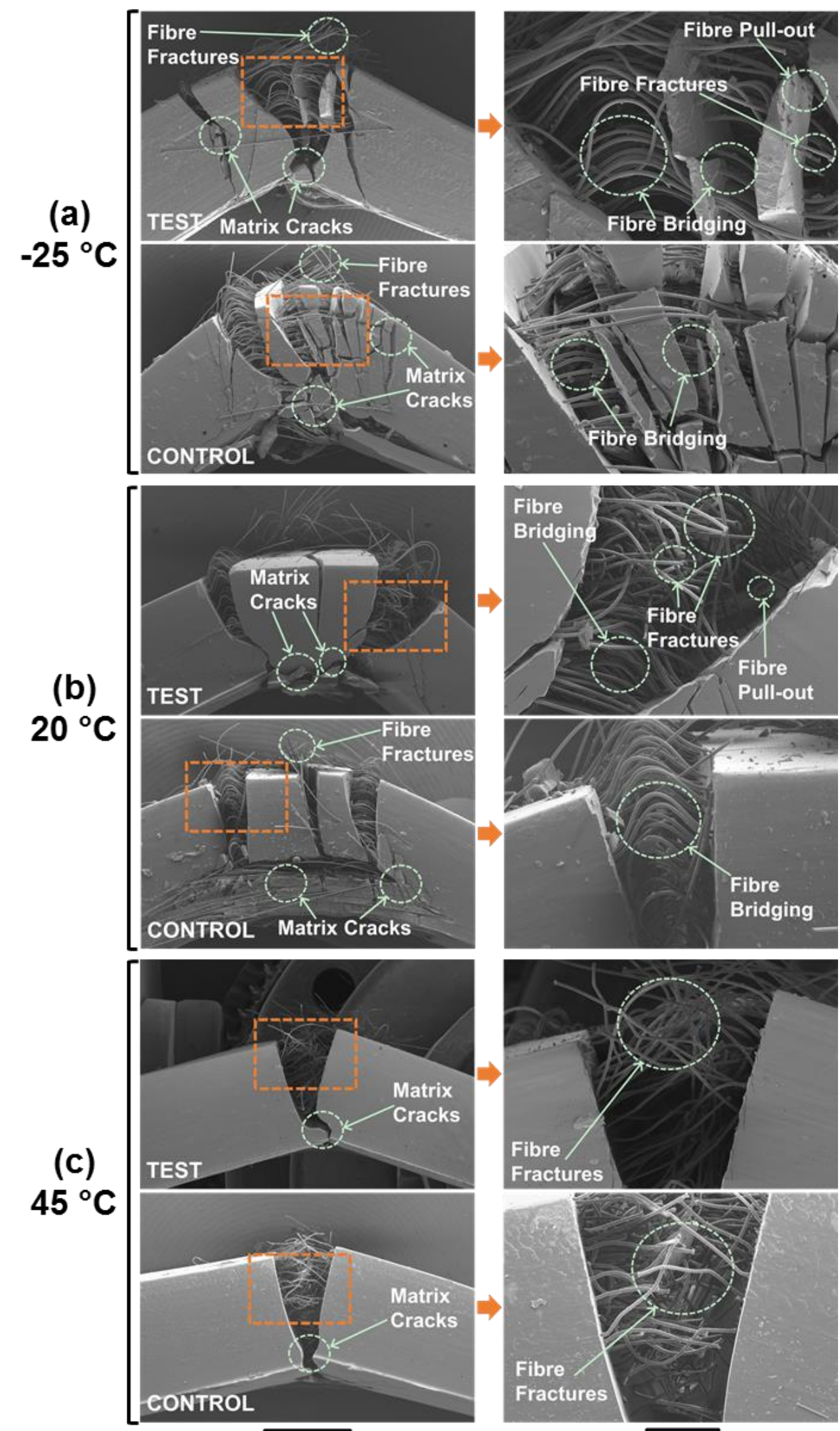

$\overline{2 \mathrm{~mm}}$

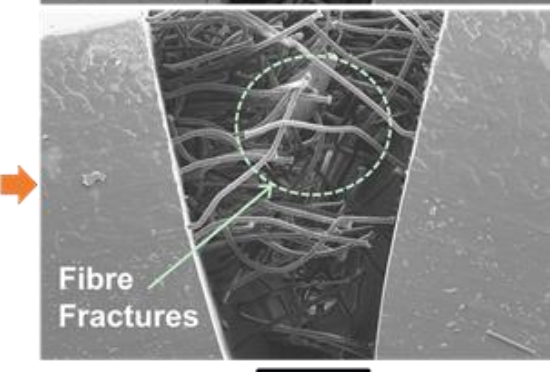

$\overline{500 \mu \mathrm{m}}$

Fig. 7. Side-view SEM images of representative test and control samples after Charpy impact tests at (a) $-25^{\circ} \mathrm{C}$, (b) $20^{\circ} \mathrm{C}$, (c) $45^{\circ} \mathrm{C}$. Higher magnification images of selected areas are shown on the right. 


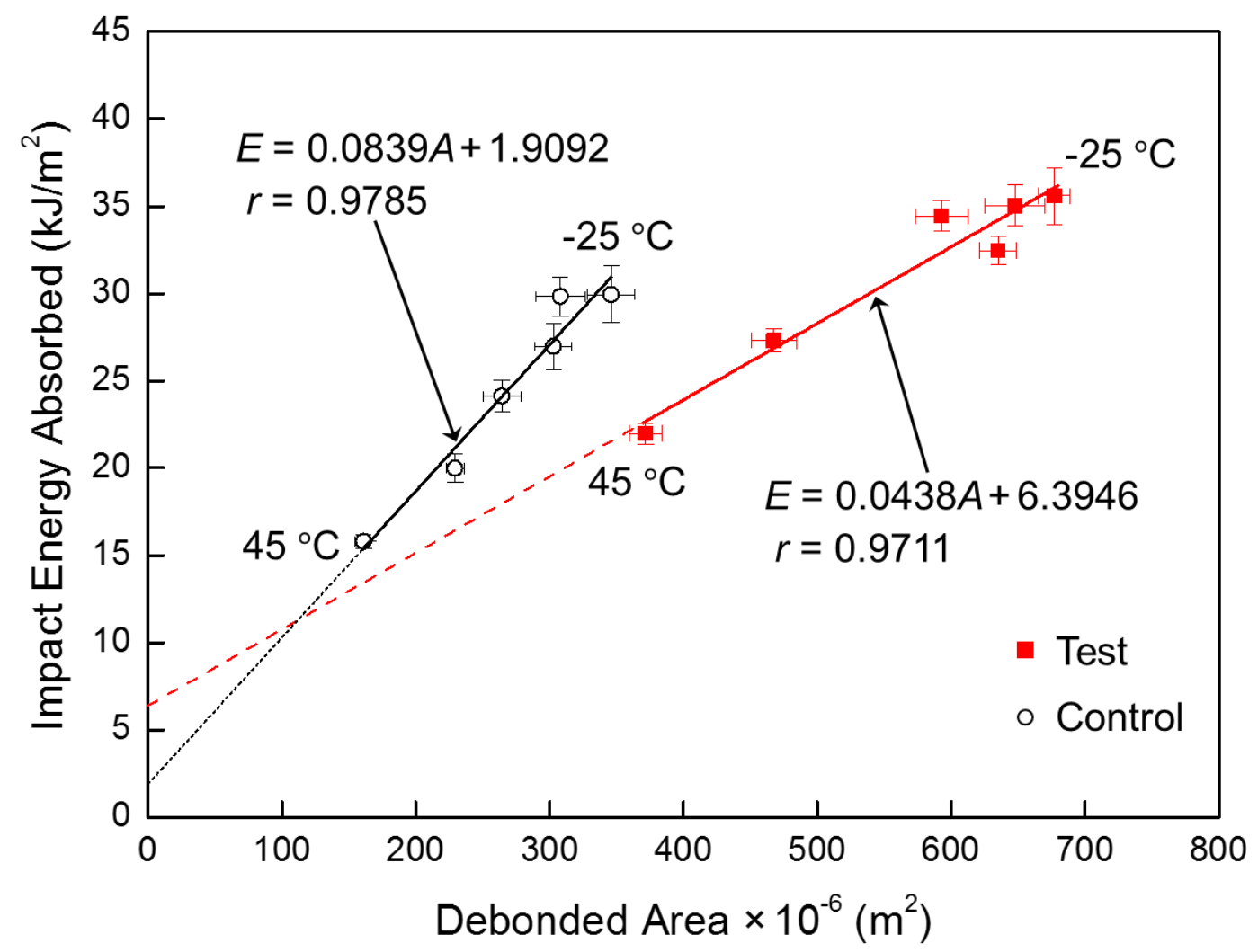

Fig. 8. Impact energies for both test and control samples plotted against sample debonded area from $25^{\circ} \mathrm{C}$ to $45^{\circ} \mathrm{C}$. Lines and equations are from linear regression; $E$ and $A$ represent energy absorbed and debonded area respectively, $r$ is the correlation coefficient. 